\title{
The rapid development of computational toxicology
}

\author{
Hermann M. Bolt ${ }^{1}\left[\right.$. Jan G. Hengstler ${ }^{1}$ \\ Received: 20 April 2020 / Accepted: 28 April 2020 / Published online: 7 May 2020 \\ (c) The Author(s) 2020
}

Ten years ago, Archives of Toxicology has issued an Editorial by R.D. Combes (2010) entitled "Is computational toxicology withering on the vine?" At that time, there was an ongoing development in the computational handling of molecular descriptors (Kirkovsky et al. 1998; Dorn et al. 2008) and in statistical methodologies (Valerio et al. 2010). There was a perspective for applications of computational methods in general both in pharmacology (Valerio 2009) and in regulatory toxicology (Lilienblum et al. 2008). However, a weakness hindering wider application of statistical in silico systems was often missing or weak external validation, mostly due to a lack of a sufficient number of test chemicals that were not used in the training set (Combes 2010). Explicit guidance on how to use the output of computational models in the range of regulatory context had not yet been developed (Mostrag-Szlichtyng et al. 2010).

In the following, important research lines of computational toxicology were the development and refinement of computational models for relevant toxicological endpoints, such as liver injury, cardiotoxicity, renal toxicity and genotoxicity (Ekins 2014). Best predictions were obtained combining different tools, to comply with particular situations (Carrió et al. 2016).

As far as regulatory acceptance is concerned, a decisive breakthrough was the integration of (Q)SAR methodologies into the guideline ICH M7 "Assessment and control of DNA-reactive (mutagenic) impurities in pharmaceuticals to limit potential carcinogenic risk", issued by the International Council for Harmonisation of Technical Requirements for Pharmaceuticals for Human use (Amberg et al. 2016; Hasselgren and Myatt 2018): in the absence of adequate experimental data, results of two complementary (Q)SAR methodologies (rule based and statistically learning based)

Hermann M. Bolt

bolt@ifado.de

1 Department of Toxicology, Leibniz Research Centre for Working Environment and Human Factors at TU Dortmund (IfADo), Ardeystr. 67, 44139 Dortmund, Germany were considered adequate to support an initial hazard classification (Tung et al. 2020), which may be followed by an assessment of additional information in an expert review to support or refute the computational predictions (Amberg et al. 2016). Similarly, also in regulatory fields other than pharmaceuticals, in silico models received increased acceptance. An example is prioritization of heat-induced food contaminants for mutagenicity and carcinogenicity testing (Frenzel et al. 2017).

A burst in manuscript submissions to "Archives of Toxicology" covering the in silico/computational field is noticed since 2019, signaling both increased scientific importance and regulatory relevance in the twenty-first century of this research area (Krewski et al. 2020). The following trends are visible:

- Advanced computational methodologies (Kusko and Hong 2019) enable progress in fields that had been difficult to cover before. Apart from the more classical applications, substantial progress is now noted in areas such as exposure assessment (Krewski et al. 2020), sensitization (Tung et al. 2019), neurotoxicity (Kosnik et al. 2020) and even developmental/reproductive toxicity (Manganelli et al. 2020; Tung et al. 2020).

- Perspectives are emerging for computational approaches to predict the toxicity of nanomaterials (Buglak 2019) and of chemical mixtures (Klar and Leszczynski 2019).

- Computational toxicology continues to assist in refining PBPK modelling (Savvateeva et al. 2020) and in exploring modes of toxic action (Ning et al. 2019; Yang et al. 2019; Hengstler et al. 2020).

A current tendency, both in the United States (Kosnik et al. 2020) and in Europe (Mahony et al. 2018), is the availability of curated public and commercial databases in the future ("Big Data"), suitable for application of hierachial clustering and machine learning. A close interplay is envisaged between such Big Data, the refinement of predictive models, toxicological experimentation and mechanistic modelling (Kleinstreuer et al. 2020). 
Given this exciting development, further submissions of manuscripts from these fields to Archives of Toxicology are highly encouraged!

Acknowledgements Open Access funding provided by Projekt DEAL.

\section{Compliance with ethical standards}

Conflict of interest The authors declare that they have no conflict of interest.

Open Access This article is licensed under a Creative Commons Attribution 4.0 International License, which permits use, sharing, adaptation, distribution and reproduction in any medium or format, as long as you give appropriate credit to the original author(s) and the source, provide a link to the Creative Commons licence, and indicate if changes were made. The images or other third party material in this article are included in the article's Creative Commons licence, unless indicated otherwise in a credit line to the material. If material is not included in the article's Creative Commons licence and your intended use is not permitted by statutory regulation or exceeds the permitted use, you will need to obtain permission directly from the copyright holder. To view a copy of this licence, visit http://creativecommons.org/licenses/by/4.0/.

\section{References}

Amberg A, Beilke L, Bercu J, Bower D et al (2016) Principles and procedures for implementation of ICH M/ recommended (Q)SAR analyses. Regul Toxicol Pharmacol 77:13-24

Buglak AA, Zherdev AV, Dzantiev BB (2019) Nano-(Q)SAR for cytotoxicity prediction of engineered nanomaterials. Molecules 24:4537. https://doi.org/10.3390/molecules24244537

Carrió P, Sanz F, Pastor M (2016) Toward a unifying strategy for the structure-based prediction of toxicological endpoints. Arch Toxicol 90:2445-2460

Combes RD (2010) Is computational toxicology withering on the vine? Arch Toxicol 84:333-336

Dorn SB, Degen GH, Bolt HM, van der Louw J, Van Acker FAA, den Dobbelsteen DJ, Lommerse JPM (2008) Some molecular descriptors for non-specific chromosomal genotoxicity based on hydrophobic interactions. Arch Toxicol 82:3334-3338

Ekins S (2014) Progress in computational toxicology. J Pharmacol Toxicol Methods 69:115-140

Frenzel F, Buhrke T, Wenzel I, Andrack J, Hielscher J, Lampen A (2017) Use of in silico models for prioritization of heat-induced food contaminants in mutagenicity and carcinogenicity testing. Arch Toxicol 91:3157-3174

Hasselgren C, Myatt GJ (2018) Computational toxicology and drug discovery in computational toxicology: methods and protocols. Meth Mol Biol 1800:233-244. https://doi. org/10.1007/978-1-4939-7899-1_11

Hengstler JG, Sjögren AK, Zink D, Hornberg JJ (2020) In vitro prediction of organ toxicity: the challenges of scaling secondary mechanisms of toxicity. Arch Toxicol 94:353-356

Kar S, Leszczynski J (2019) Exploration of chemical approaches to predict the toxicity of chemical mixtures. Toxics 7:15. https://doi. org/10.3390/toxics7010015

Kirkovsky LI, Lermontov SA, Zavorin SI, Sukhozhenko II, Zavelsky VI, Thier R, Bolt HM (1998) Hydrolysis of genotoxic methyl-substituted oxiranes: experimental kinetic and semiempirical studies. Environ Toxicol Chem 17:2141-2147. https://doi. org/10.1002/etc.5620171103

Kleinstreuer NC, Tong W, Tetko IV (2020) Computational toxicology. Chem Res Toxicol 33:687-688

Kosnik MB, Strickland JD, Marvel SW, Wallis DJ, Wallace K, Richard AM, Reif DM, Shafer TJ (2020) Concentration-response evaluation of ToxCast compounds for multivariate activity patterns of neuronal network function. Arch Toxicol 94:469-484

Krewski D, Andersen ME, Tyshenko MG, Krishnan K, Hartung T, Boekelheide K, Warmbaugh JF, Jones D, Whelan M, Thomas R, Yauck C, Barton-Maclaren T, Cote I (2020) Toxicity testing in the 21st century: progress in the past decade and future perspectives. Arch Toxicol 94:1-58

Kusko R, Hong H (2019) Computational toxicology promotes regulatory science. Chall Adv Comput Chem Phys. https://doi. org/10.1007/978-3-030-16443-0_1

Lilienblum W, Dekant W, Foth H, Gebel T, Hengstler JH, Kahl R, Kramer PJ, Schweinfurth H, Wollin KM (2008) Alternative methods to safety studies in experimental animals: role in the risk assessment of chemicals under the new European Chemicals Legislation (REACH). Arch Toxicol 82:211-236

Mahony C, Currie R, Daston G, Kleinstreuer N, van de Water B (2018) Highlight report: 'Big data in the 3R's: outlook and recommendations', a roundtable summary. Arch Toxicol 92:1015-1020

Manganelli S, Schilter B, Scholz G, Benfenati E, Lo Piparo E (2020) Value and limitation of structure-based profilers to characterize developmental and reproductive toxicity potential. Arch Toxicol 94:939-954

Mostrag-Szlichtyng A, Zaldívar Comenges JM, Worth AP (2010) Computational toxicology at the European Commission's Joint Research Centre. Expert Opin Drug Metab Toxicol 6(7):785-792

Ning J, Chen L, Strikwold M, Louisse J, Wesseling S, Rietjens IMCM (2019) Use of an in vitro-in silico testing strategy to predict interspecies and inter-ethnic human differences in liver toxicity of the pyrrozolidine alkaloids lasiocarpine and riddeline. Arch Tocicol 93:801-818

Savvateeva D, Numata J, Pieper R, Schafft H, Lahrssen-Wiederholt M, Bulik S (2020) Physiologically based toxicokinetic models and in silico predicted partition coefficients to estimate tetrachlorodibenzo-p-dioxin transfer from feed into growing pigs. Arch Toxicol 94:187-196

Tung CW, Lin YH, Wang SS (2019) Transfer learning for predicting human sensitizers. Arch Toxicol 93:931-940

Tung CW, Cheng HJ, Wang CC, Wang SS, Lin P (2020) Leveraging complementary computational models for prioritizing chemicals of developmental and reproductive toxicity concern: an example of food contact materials. Arch Toxicol 94:485-494

Valerio LG (2009) In silico toxicology for pharmaceutical sciences. Toxicol Appl Pharmacol 241:356-370

Valerio LG (2010) Computational science in drug metabolism and toxicology. Expert Opin Drug Metab Toxicol 6(7):781-784

Yang H, Du Z, Lv WJ, Zjang XY, Zhai HL (2019) In silico toxicity evaluation of dioxins using structure-activity relationship (SAR) and two-dimensional 1nantitative structure-activity relationship (2D-QSAR). Arch Toxicol 93:3207-3218

Publisher's Note Springer Nature remains neutral with regard to jurisdictional claims in published maps and institutional affiliations. 